\title{
Espectro clínico de la Enfermedad de Castleman
}

\author{
The clinical spectrum of Castleman's disease
}

\author{
María Rebeca Guzmán-Fernández, Fiz Campoy-García, María Pereiro-Sánchez, José Luis Sastre-Moral \\ Servizo de Hematología. Complexo Hospitalario Universitario de Ourense. SERGAS. Ourense
}

\begin{abstract}
Resumen
La enfermedad de Castleman (EC) es una enfermedad hematológica rara caracterizada por hiperplasia de nódulos linfoides con dos patrones histológicos y clínicos bien diferenciados: hialino-vascular que suele ser unicéntrico, de comportamiento poco agresivo y cuya exeresis consigue la curación en la mayor parte de los casos. La variante plasmocelular es más agresiva, su presentación clínica remeda los linfomas de alto grado y requiere quimioterapia para su erradicación. Juegan un papel etiopatogenico el HVH-8 y las interleucinas IL-6 e IL-1. Nuevos fármacos basados en el bloqueo de la IL-6 o su receptor han demostrado recientemente su utilidad para el control de la enfermedad. Presentamos casos que representan el espectro de la EC.

Palabras clave: Enfermedad de Castleman, Hiperplasia linfoide, hiperplasia angiofolicular, HVH-8, interleucina-6, rituximab, tocilizumab.
\end{abstract}

\section{Introducción}

La enfermedad de Castleman (EC) es una patología hematológica rara también llamada hiperplasia linfoide angiofolicular que se caracteriza por hiperplasia de nódulos linfoides. Fue descrita por primera vez en 1956 por Benjamín Castleman quien evidenció en una serie de pacientes la presencia de nódulos linfáticos hiperplásicos solitarios con folículos hialinos y una marcada proliferación vascular ${ }^{1}$. Posteriormente se definieron los dos patrones histológicos con los que se puede presentar esta enfermedad: el primero conocido como hialinovascular y el segundo como variante plasmocelular (Tabla 1). Desde el punto de vista clínico a éstos, por tener una afección localizada, se les englobó dentro del tipo unicéntrico. En 1972 se reconoció otra forma clínica con expresión periférica generalizada y afectación sistémica denominada multicéntrica'.

Al ser una patología poco frecuente su incidencia en la población es difícilmente estimable. Se presenta con igual frecuencia en ambos sexos y puede aparecer a cualquier edad, predominan-

\section{Abstract}

Castleman's disease (CD) is a rare hematological disease characterized by hyperplasia of lymphoid nodules with two distinct histological and clinical patterns: hyaline - vascular which is usually single-center, low and aggressive behavior which gets exeresis healing in most of cases. The plasma cell variant is more aggressive clinical presentation mimics highgrade lymphomas and requires chemotherapy to eradicate. Play an etiopathogenic role HHV -8 and IL -6 and IL -1 cytokines. New drugs based on the blockade of $\mathrm{IL}-6$ or its receptors have recently proved useful in the control of the disease. We present cases representing the spectrum of $\mathrm{CD}$.

Keywords: Castleman's disease, lymphoid hyperplasia, hyperplasia angiofollicular, HHV-8, interleukin-6, rituximab, tocilizumab.

temente entre la tercera y quinta década de la vida. En una serie británica de 416 pacientes presentada por Talaty colaboradores se evidenciaba que en décadas tempranas de la vida es más frecuente en mujeres con la forma unicéntrica e hialinovascular, mientras que por encima de la cuarta década era más frecuente en varones con enfermedad multicéntrica².

\section{Etiopatogenia e histología}

En su fisiopatología intervienen múltiples factores biológicos que producen una desregulación inflamatoria traducida en proliferación linfovascular. Estudios realizados en animales demostraron que en casos de EC se encontraba elevada la lL-6 y que al resecar el ganglio solitario se normalizaban las anomalías biológicas y las manifestaciones clínicas ${ }^{3}$. Su importante rol también queda demostrado ex juvantivus con el uso de anticuerpos anti IL-6 que son capaces de limitar la progresión de la enfermedad ${ }^{4}$. También se ha encontrado relación con el Herpes virus humano 8 (HVH-8), un virus linfotrópico humano que puede producir una proteína homóloga a la IL-6 capaz tanto de unirse al receptor

Tabla 1.- Descripción histológica de las variantes de presentación de la EC

\begin{tabular}{|ll|}
\hline VARIANTES DE EC & CARACTERÍSTICAS HISTOLÓGICAS \\
\hline HIALINOVASCULAR & $\begin{array}{l}\text { Presencia de atrofia del centrogerminal rodeado por una zona de manto con linfocitos pequeños con organización en } \\
\text { capas de cebolla, que posteriormente pasara por un proceso de hialinización. También contiene en la zona interfolicular } \\
\text { proliferación vascular con sinusoides típicamente obliterados. }\end{array}$ \\
PLASMOCELULAR & $\begin{array}{l}\text { Hiperplasia centrogerminal con la región interfolicular formada por capas de células plasmáticas e } \\
\text { hipervascularización. }\end{array}$ \\
MIXTA & $\begin{array}{l}\text { Presenta en la misma zona folicular linfática degeneración hialina con capas de células plamáticas mostrando patrones } \\
\text { de los dos grupos descritos anteriormente. }\end{array}$ \\
\hline
\end{tabular}


correspondiente en la célula huésped y activar transcripción como de ejercer su acción de forma independiente. Además la $\| \mathrm{L}-1$, al igual que la IL-6, se encuentra sobreexpresada en los pacientes con EC por la regulación aberrante del sistema inmune 5 . El resultado histológico de estas alteraciones es una hiperplasia centrogerminal, con acumulación de inmunoblastos y células plasmáticas e incremento de la vascularidad como una reacción exagerada a un estímulo antigénico ${ }^{6}$. La biopsia del nódulo linfático patológico es la prueba diagnóstica definitiva de la enfermedad de Castleman. Se evidencia en ella el patrón hialinovascular 0 la infiltración de células plasmáticas dependiendo de la variedad. En el caso de presentar afectación de múltiples cadenas linfáticas las zonas de elección para la biopsia ganglionar en orden de preferencia son: supraclavicular, cuello, axila e ingle ${ }^{7}$. Con la inmunohistoquímica para antígenos virales se ha demostrado la presencia del HVH-8 en un $10-30 \%$ de las células linfoides de la zona del manto en pacientes HVH-8 con ECM. Estas células tienen una morfología inmunoblástica con una positividad variable de CD20 y expresan positividad para el factor de transcripción MUM1/RF4. Todas las células infectadas expresaron altos niveles de lgM lambda lo que se respalda en los estudios in vitro donde existe afinidad del virus por células B que expresen inmunoglobulina lgM lambda. No se han observado hipermutaciones somáticas del gen de inmunoglobulinas por lo que se asume el origen en las células $B$ virgen 0 células $\mathrm{B}$ memoria que expresen lgM8.

Presentamos someramente un caso clínico de enfermedad de Castleman multicéntrico y la tabla 2 con los datos más relevantes de otros casos tratados recientemente en nuestro centro.

\section{Caso clínico}

Varón de 62 años de edad diabético, con enfermedad broncopulmonar obstructiva crónica asociado a síndrome de apnea obstructiva del sueño. Presentó un cuadro de 4 meses de evolución con astenia, pérdida de peso y apetito, diaforesis y picos febriles sin filiación microbiológica. En la exploración física presentaba adenopatías de tamaño patológico a nivel cervical y axilar con hepatoesplenomegalia. En la analítica se evidenció anemia normocítica normocrómica, VSG elevada e hipergammaglobulinemia policlonal, serología negativa para VIH pero positiva para VHH-8. En TAC toracoabdominopelvico se demostraron importantes conglomerados adenopáticos tanto supra como infradiafragmáticos (Figura 1). La biopsia adenopática axilar demostró hiperplasia centrogerminal con proliferación de células plasmáticas compatible con enfermedad de Castleman en su variante multicéntrica-plamocelular. La médula ósea no estaba infiltrada. Se inició tratamiento con prednisona $30 \mathrm{mg} /$ día durante la primera semana con mejoría clínica discreta. Subsecuentemente se pautó quimioterapia con esquema R-CHOP. Tras el cuarto ciclo se objetivó respuesta parcial con disminución significativa de conglomerados adenopáticos en TAC de seguimiento. Tras 8 ciclos de R-CHOP el paciente alcanzó criterios de respuesta morfológica completa. Se consideró la consolidación de la respuesta con trasplante autólogo de progenitores hematopoyéticos acondicionado con esquema CVB (ciclofosfamida + VP16 + BCNU). En el $5^{\circ}$ mes post-trasplante el paciente continúa asintomático libre de enfermedad.

Figura 1. TAC de tórax: se visualiza en un mismo corte tomográfico la afectación axilar y paratraqueal de la ECM

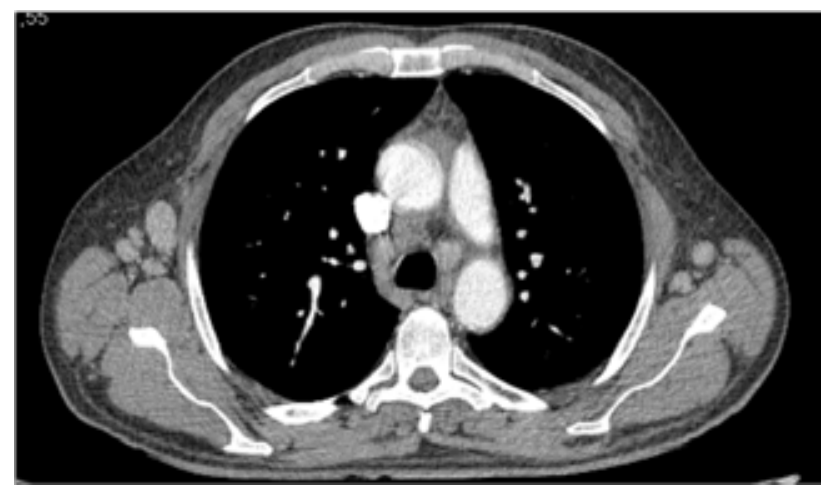

\section{Discusión}

En este epígrafe abordaremos fundamentalmente cuestiones referentes al diagnóstico y tratamiento de la enfermedad de Castleman.

Tabla 2. Descripción de casos clínicos.

\begin{tabular}{|c|c|c|c|c|c|c|c|c|}
\hline Paciente & Edad & Sexo & Presentación & Histología & VIH & HVH-8 & Tratamiento & Recaída \\
\hline 1 & $62 \mathrm{a}$ & $\mathrm{M}$ & Multicéntrico & Plasmo-celular & - & + & R-CHOP y TASPE & No \\
\hline 2 & $39 \mathrm{a}$ & $\mathrm{M}$ & Multicéntrico & Hialino-vascular & - & + & $\begin{array}{c}\text { R-CHOP y ESAP, } \\
\text { intensificación con } \\
\text { TASPE }\end{array}$ & $\begin{array}{c}24 \text { meses } \\
\text { Exitus }\end{array}$ \\
\hline 3 & $45 \mathrm{a}$ & $\mathrm{M}$ & Unicéntrico & Hialino-vascular & - & + & Cirugía & No \\
\hline 4 & $36 \mathrm{a}$ & $\mathrm{M}$ & Unicéntrico & Mixto & - & - & Cirugía & No \\
\hline
\end{tabular}




\section{Diagnóstico}

La presentación clínica dependerá del subtipo de enfermedad. La variedad unicéntrica, frecuentemente asintomática, se diagnostica incidentalmente por estudios de imagen. La zona comúnmente afectada son los ganglios mediastínicos, de los hilios pulmonares y cadena cervical en orden de frecuencia. Solo algunos casos con histología plasmocelular presentaron síntomas secundarios a anemia2,4,7. La EC multicéntrica presenta clínica inespecífica y síntomas B como pérdida de peso, anorexia, fiebre sin foco aparente, sudoración nocturna. Solo un 10\% de los pacientes son asintomáticos $2,4,7$.

Los hallazgos de laboratorio más frecuentes son anemia, hipoalbuminemia, hipergammaglobulinemia, aumento velocidad de sedimentación globular y de gran variedad de citoquinas, notablemente de IL-6 e IL-14,7. Son imprescindibles las de serologías de VIH y HVH-8 en vista de la importante relación en la patogenia de la enfermedad.

La tomografía axial computarizada demuestra los nódulos linfáticos patológicos mediastínicos e hiliares principalmente; también se puede encontrar afectación pulmonar con un patrón reticular en vidrio deslustrado, engrosamientos pleurales y en menor proporción presencia de nódulos pulmonares ${ }^{7}$.

\section{Tratamiento}

Para el manejo de la EC disponemos de una amplia gama de opciones terapéuticas con un nivel de recomendación bajo por la escasa evidencia científica derivada del hecho de tratarse de una enfermedad poco frecuente de la que apenas existen ensayos clínicos ni estudios aleatorizados.

La variedad unicéntrica con afectación localizada se beneficia de la resección del ganglio patológico con una alta tasa de curación posterior8. En los casos de acceso quirúrgico difícil 0 de compleja exéresis el uso de radioterapia es una buena alternativa, pero es curativa en menos del $50 \%$ de los casos ${ }^{9}$.

En cuanto a la variedad multicéntrica la decisión es más complicada y el pronóstico menos favorable. Se han probado múltiples líneas terapéuticas sin alcanzar consenso sobre la pauta de elección. Se ha empleado monoterapia con clorambucilo, corticoides, ciclofosfamida, vincristina y bleomicina, aunque solo se ha demostrado remisión duradera de la enfermedad con doxorrubicina liposomal y etopósido oral. También existe buena experiencia con etopósido a dosis de $100 \mathrm{mg} / \mathrm{m}^{2} \mathrm{IV}$ durante cuatro semanas. Como norma general debemos considerar que Ios fármacos administrados como monoterapia son paliativos y la enfermedad recurre tras un tiempo variable una vez finalizado el tratamiento $0^{4,7}$.

También existen publicaciones de pacientes tratados con esquemas quimioterápicos utilizados para linfoma no Hodgkin, principalmente ciclofosfamida, doxorubicina, vincristina y prednisona (CHOP) solo o combinado con altas dosis de melfalán seguido de trasplante autólogo de progenitores hematopoyéticos. La combinación de CHOP y rituximab ha sido poco estudiada en enfermedad multicéntrica, pero cabe pensar a priori que sería efectiva. Con menos frecuencia se han reportado clorambucilo-prednisona, ciclofosfamida-prednisona y ciclofosfamidaprocarbazina ${ }^{7}$.

Para los pacientes con fallo multiorganico o con mal estado general se sugiere el uso de rituximab (grado 2C) ${ }^{7}$. Rituximab es un anticuerpo monoclonal dirigido contra el antígeno CD20 de las células B que provoca linfodeplección por citotoxicidad asociada a anticuerpos 0 activación del complemento ${ }^{7,10}$. Ha demostrado respuestas duraderas usado en monoterapia y en combinación con quimioterapia. Es un fármaco bien tolerado y sus efectos secundarios son manejables. Conviene recordar su uso prudente en pacientes infectados por VHB. Algunos investigadores aconsejan no usar en pacientes $\mathrm{VIH}+$ mal controlados o con sarcoma de Kaposi ya que se ha descrito progreso de ambas enfermedades durante el tratamiento ${ }^{11}$.

Los corticosteroides consiguen paliar los síntomas B hasta que se inicia la quimioterapia agresiva en un 60 a $70 \%$ de los pacientes, como ocurrió con nuestro paciente en la primera semana de ingreso. La mejoría suele ser de corta duración usados aisladamente. No obstante, su mayor utilidad es la combinación con otras drogas citotóxicas en esquemas tales como CHOP y CVAD. No se ha demostrado eficacia en pacientes $\mathrm{VIH}+$ con $\mathrm{ECM}^{4,7}$.

Otros agentes inmunomoduladores como el Interferón-alfa producen beneficios significativos tanto en pacientes VIH infectados como los no infectados. Se explicaría tanto por el efecto regulador del sistema inmune al inhibir la señalización a través del receptor IL-6 como por su actividad anti retroviral inhibiendo la replicación del VHH-87. Por su parte, la talidomida regula la expresión de IL-6 y factor de necrosis tumoral alfa siendo esta acción la que probablemente resulte beneficiosa para la limitación de la enfermedad. Se ha observado una respuesta sostenida tras 4 años una vez discontinuado el tratamiento con bortezomib, un agente útil en el mieloma múltiple que disminuye los niveles de IL-6 ${ }^{12}$.

Con los avances en el conocimiento de la biología de la enfermedad están irrumpiendo con fuerza los nuevos agentes biológicos para inmunoterapia dirigida. Con los inhibidores de la IL-6 o su receptor existen varios estudios que demuestran resultados prometedores. Uno de ellos, el tocilizumab, anticuerpo monoclonal humanizado contra el receptor de esta interleucina revirtió los parámetros inflamatorios, disminuyó los síntomas clínicos y la magnitud de las adenopatías con muy buena tolerancia $^{13}$. Otra opción terapéutica de esta familia es el siltuximab que bloquea directamente la acción de IL-6 obteniendo buenas respuestas sin problemas de tolerancia ni toxicidad. Pero aún está pendiente la valoración de la respuesta a largo plazo, pues, en algunos pacientes con enfermedad multicéntrica tratados con siltuximab, los beneficios fueron transitorios y los síntomas recurrieron precozmente cuando este fue suspendido ${ }^{14}$. 
Figura 2.- Enfermedad de Castleman: (A) degeneración hialina con proliferación vascular en variante hialino-vascular. (B) Células plasmáticas con inclusiones citoplasmática de cuerpos de Russell. (C) Organización en capas de cebolla de células plasmáticas

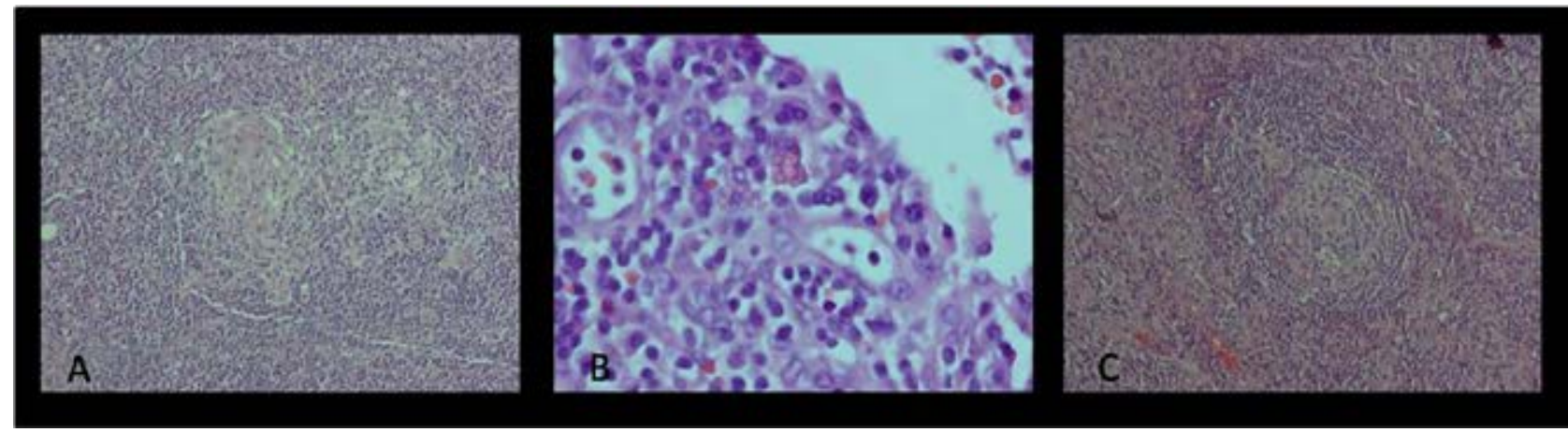

Desde que se demostró la relación posible entre esta patología y la infección viral por el VHH-8 el manejo y control de la replicación del virus se convirtió en una diana terapéutica. Solo ganciclovir, foscarnet y cidofovir han demostrado actividad in vitro contra el virus. En el caso de ganciclovir se han reportado dos casos de buena respuesta con su uso por vía intravenosa coincidiendo con la supresión completa de la replicación viral. En cambio con cidofovir no se evidenció respuesta ni tampoco disminución de la carga viral en sangre periférica ni a nivel de células mononucleares del $\mathrm{VHH}-8^{15}$.

Con relación al VIH/SIDA desde la implantación de la terapia antiretroviral altamente activa ha cambiado dramáticamente el curso natural de la enfermedad aumentando la supervivencia. Estudios realizados en pacientes seropositivos y con ECM se ha observado la exacerbación de la enfermedad concordando con el inicio de la terapia atribuido este evento al síndrome de reconstitución inmune secundario. Pero aun así la supervivencia global y la progresión a linfoma de EC es de un 10 a 20\% menor en pacientes $\mathrm{VIH}+$ desde el inicio de la terapia altamente activa. Por lo que su efecto en la enfermedad todavía no está muy claro. En el caso referido más arriba nuestra intención terapéutica ha sido curativa y por ello hemos utilizado un planteamiento global con el esquema estándar de los linfomas agresivos CD20+ como es la administración de 8 ciclos de R-CHOP y consolidado la buena respuesta conseguida con un trasplante autólogo de precursores hemopoyéticos. El seguimiento determinará si el mismo ha sido acertado. En el caso de recidiva disponemos de los inhibidores de $\| \mathrm{L} \cdot 6$ para controlar nuevamente la enfermedad a medio plazo y considerar otros regímenes quimioterápicos de rescate.

\section{Bibliografía}

1. Castleman B, Iverson L, Menendez VP. Localized mediastinal lymph-node hiperplasia resembling thymoma. Cancer 1956; 9: 822-830.

2. Talat N , Schulte KM. Castleman's disease: systematic analysis of 416 patients from the literatura. Oncologist 2011; 16: 1316-1324.

3. Katsume A, Saito H, Yamada Y et al. Anti-interleukine 6 (IL-6) receptor antibody supresses Castleman's disease like symptoms emerged im IL-6 transgenic mice. Cytokine 2002; 20: 304-311.

4. El-Osta H, Kurzrock R. Castleman's disease from basics mechanisms to molecular therapeutics. The Oncologist 2011; 16: 497-511.

5. Gherardi RK, Belec L, Fromont $\mathrm{G}$ et al. Elevated levels of interleukine 1 beta (IL-1beta) in serum anf incresed production of IL-1 mRNA in lymph-nodes of patienst with polyneuropathy, organomegaly, enocrynopathy, M protein and skin changes (POEMS) syndrome. Blood 1994; 83: 2587-2593.

6. Sullivans RJ, Patanowitz L, Casper C et al. HIV/AIDS: Epidemiology, pathophisiology and treatment of Kaposi sarcoma asociated herpesvirus disease: Kaposi sarcoma, primary effusion lymphoma and multicentric Castleman's disease. Clin infect dis 2008; 47: 1209-1215.

7. Aster JC, Brown JR. Catleman's disease. Uptodate 2013.

8. Talat N, Belgaumkar A. Surgery in Castleman's disease: A systematic review of 404 published cases. Annals of surgery. 255; 4:677-684.

9. Accioli $F$, Chiquetto $V$, Viani $G$ et al. Radiation therapy in the treatment of unicentric Castleman`s disease. J Bras Pneumol. 2013; 39: 116-118.

10. Gerard L, Michot J, Burcheri S et al. Rituximab decreases the risk of lymphoma in patients with HIV-associated multicentric Castleman disease. Blood 2012; 119: 2228-2233.

11. Marcelin AG, Aaron L, Mateus C et al. Rituximab therapy for HIV associated Castleman disease. Blood 2003; 102: 2786-2788.

12. Sobas MA, Alonso VN, Diaz A et al. Efficacy of bortezomib in refractory form of multicentric Castleman's desease associated POEMS syndrome. Ann Hematol 2010; 89: 217-219.

13. Turcotte $L$, Correll K, Reed $R$ et al. Sustained remission of severe multicentric Castleman disease following multiagent chemotherapy and tozilizumab maintenance. Pediatr blood cáncer 2014; 61: 737-739.

14. Van Rhee $F$, Voorhees $P$ et al. Siltuximab, a nobel anti-interleukin 6 monoclonal antibody for Castleman’s disease. J Clin Oncol 2010; 28: 3701-3708.

15. Casper $\mathrm{C}$. New approaches to the treatment of human herpesvirus 8-associated disease. Rev Med Virol 2008;18:321-329 